\title{
LIDAR DERIVED PROPERTIES OF AIR-MASSES ADVECTED FROM UKRAINE, SAHARA AND CARPATHIAN MOUNTAINS TO WARSAW, POLAND ON 9 - 11 AUGUST 2015
}

\author{
Lucja Janicka $^{1}$, Dominika Szczepanik ${ }^{1}$, Karolina Borek ${ }^{1}$, Birgit Heese ${ }^{2}$, \\ Iwona S. Stachlewska ${ }^{1}$ \\ ${ }^{1}$ University of Warsaw, Faculty of Physics, Institute of Geophysics, Warsaw, Poland, \\ iwona.stachlewska@igf.fuw.edu.pl \\ ${ }^{2}$ Leibnitz Institute for Tropospheric Research, Leipzig, Germany
}

\begin{abstract}
The aerosol layers of different origin, suspended in the atmosphere on 9-11 August 2015 were observed with the PollyXT-UW lidar in Warsaw, Poland. The HYSPLIT ensemble backward trajectories indicate that the observed air-masses attribute to a few different sources, among others, possible transport paths from Ukraine, Slovakia, and Africa. In this paper, we attempt to analyse and discuss the properties of aerosol particles of different origin that were suspended over Warsaw during this event.
\end{abstract}

\section{INTRODUCTION}

At the end of July a heat-wave span over Europe, causing in some countries absolute temperature records, e.g. $40.3^{\circ} \mathrm{C}$ record in Germany. In Poland, the temperatures were slightly lower, still from August $2^{\text {nd }}$, we had to face one of the biggest heat waves on record; until August $15^{\text {th, }}$ the temperatures very often exceeded $35^{\circ} \mathrm{C}$. At the beginning of the second half of the month, it became significantly cooler, still high temperatures were observed untill the end of the month. In general, August 2015 proved to be an exceptionally warm month, with the positive temperature anomaly of $4.71 \mathrm{~K}$ as calculated in relation to the period 1961-1990 and of $3.73 \mathrm{~K}$ to the period 1981-2010. It was also the warmest August in Poland after 1807.During the first two weeks of August 2015, extremely dynamical weather conditions were caused by a stationary front, which was located in the high pressure system that was formed over Europe. Such special weather conditions may contribute to an advection of multiple layers of several air-masses. These can be observed only by the means of the quasi- continuous ground-based or satellite lidar observations. For such multi-layer cases, interpretation of the passive remote sensors that provide information on the spectrally dependent columnar aerosol optical depth is practically impossible.

Here we discuss lidar derived particle properties characteristic for different aerosol layers that were suspended in the atmosphere over Warsaw from $9^{\text {th }}$ to $11^{\text {th }}$ August 2015. The detected layers are characterized by distinctively different properties and origin. We measured biomass burning particles from wild fires in Ukraine, the weak layer of depolarizing particles transported form Africa, and the air-masses that few days earlier circulated over Western Carpathians in Slovakia. Moreover, other layers with uncertain origin were observed, indicating possible mixtures of the above mentioned particle types.

\section{METHODOLOGY}

The Radiative Transfer Laboratory (RT-Lab) in Warsaw, Poland $\left(52.21^{\circ} \mathrm{N}: 20.98^{\circ} \mathrm{E}, 112 \mathrm{~m}\right.$ asl $)$ is equipped with the 12-channel PollyXT-UW lidar [1] built in a scientific collaboration of the UW and TROPOS. The lidar was designed as an aerosol-depolarization-Raman lidar (thus at the UW it is alternatively called the ADR Lidar), and comprises two independent detection modules, which can be applied for simultaneous data collection in the near- and far-range regime from the lidar. The main, integral unit of the lidar is the far-range unit, so-called $3 \beta+2 \alpha+2 \delta+\mathrm{WV}$ detection module, which provides quasi-automated measurements at the following 8 channels: 1064, 355 and $532 \mathrm{~nm}$ (for elastic total scattering), 532 and $355 \mathrm{~nm}$ (for elastic cross-scattering), 607 and 
$387 \mathrm{~nm}$ (Raman scattering on $\mathrm{N} 2$ ) and $407 \mathrm{~nm}$ (Raman scattering on $\mathrm{H} 2 \mathrm{O}$ ). The compact nearrange aerosol-Raman lidar receiver (NARLa) was built to enhance the lidar lower detection limit. The NARLa (so-called $2 \beta+2 \alpha$ ) is designed for 355 and $532 \mathrm{~nm}$ (elastic), and 607 and $387 \mathrm{~nm}$ (Raman N2) detection. It was installed for regular observations in April 2016 and thus the near-range data are not used here.

The PollyXT-UW lidar provides regular highquality measurements within the lidar networks: since July 2013 to the world-wide PollyNET [2] (http://polly.tropos.de) and since March 2015 to the EARLINET [3] (https://www.earlinet.org). It also delivers the data to the Polish aerosol network PolandAOD (http://www.polandaod.pl).

The lidar optical properties that are discussed in this paper were calculated using the TROPOS data evaluation software (Verlauf5GN); details on the applied evaluation scheme are given in [4]. The day and night-time optical properties profiles are derived from lidar signals using the classical approaches: particle extinction and backscatter coefficients retrieval is done with Raman channels (for all calculations Ångström exponent of 1 is assumed) [4]; the \pm 45 method is used for linear depolarization retrieval [5]; the water vapour mixing ratio and relative humidity profiles are derived as in [6] (obtained from dusk to dawn, as we measure with $407 \mathrm{~nm}$ channel during nighttime only). Thus, for evaluation of aerosol optical properties and moisture solely lidar data are used. Those are however calibrated with use of $\left(p_{0}, T_{0}\right)$ at the RT-Lab in Warsaw and the radiosonde data for $(p, T)$-profiling available at 00UTC, 12UTC at WMO12374 site in Legionowo (25km North).

\section{RESULTS AND DISCUSSION}

The multiple aerosol layers observed over Warsaw on $10^{\text {th }}$ August 2015 are shown in Fig.1.

The upper sub-figure depicts the daily evolution of the $1064 \mathrm{~nm}$ elastic signals (in arbitrary units) up to $5 \mathrm{~km}$ altitude. Note that in the lowermost range $(<600 \mathrm{~m})$, the geometrical overlap between laser beam and full field of view of the telescope is incomplete. The signals measured above $5 \mathrm{~km}$ are not shown, as above that height neither any significant aerosol signatures nor cloud systems are revealed.
The aerosol structures and layering are depicted in lower sub-figure of Fig.1. In each case, they were discerned manually based on the trajectory analyzes that was combined with the optical properties derived from the lidar measurements.

The backward-trajectories were calculated using the HYSPLIT model [7], beginning with all simulations at Warsaw location at different hours and different altitudes. Each time the model was run for 4 to 9 days using the meteorological data from the Global Data Assimilation System (GDAS). The plots of the trajectories are not shown here for brevity.

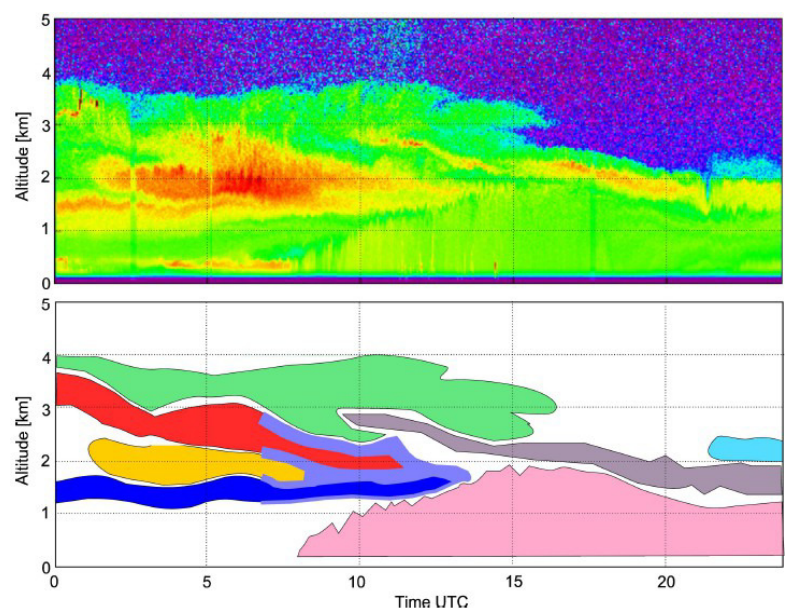

Figure 1 Lidar range corrected signal at $1064 \mathrm{~nm}$ on 10 August 2015 measured at the Radiative Transfer Laboratory RTLab in Warsaw (upper sub-figure, red colours indicate high aerosol load, blue - low) along with attributed aerosol layering based on the backtrajectory and optical properties analyses (lower subfigure, each colour defines layer described in text).

In Fig.2, the results obtained on August $10^{\text {th }}$ at about 00:00UTC and 22:00UTC from lidar data averaged over $45 \mathrm{~min}$ are shown as examples. They depict the particle backscatter coefficient profiles plotted along with the profiles of volume linear depolarization ratios. We chose these two times, as they depict what it seems to be a distinctly different composition of aerosol airmasses that were observed on that day: at 00:00 UTC profiles in Fig.2 are corresponding to the dark blue, red and green air-masses defined in the lower sub-figure of Fig.1; at 22:00 UTC profiles in Fig. 2 are corresponding to the pink, blue and grey air-masses in the lower sub-figure of Fig.1. 


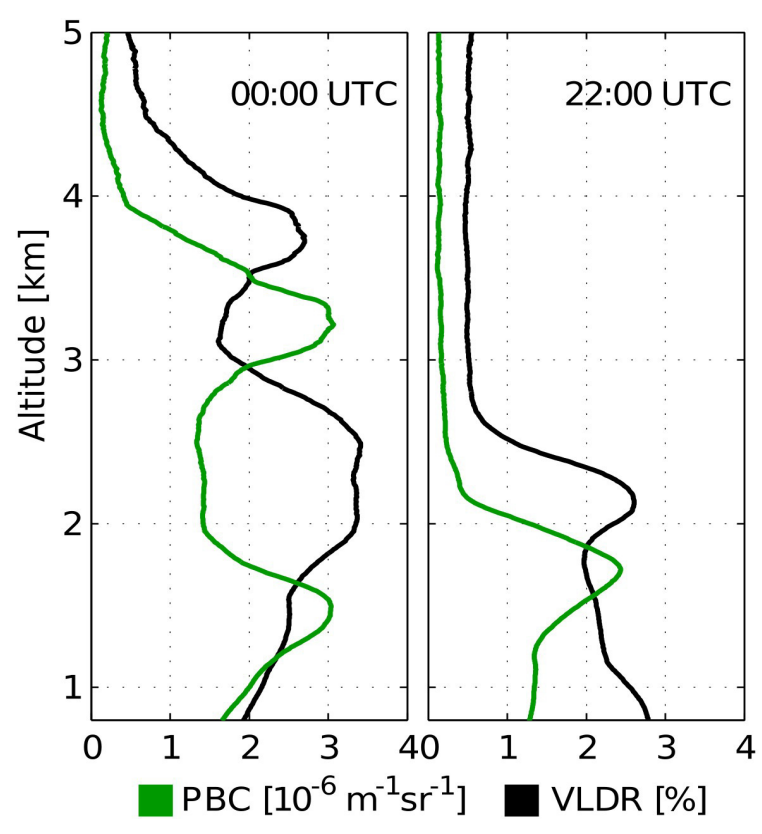

Figure 2 Profiles of the particle backscatter coefficient (in green) plotted along with the profiles of volume linear depolarization ratios (in black) obtained form the PollyXT-UW lidar in Warsaw on 10 August 2015.

As mentioned above, the HYSPLIT backward trajectory analysis and their interpretation against lidar derived aerosol optical properties and water vapor profiles (if available) was performed. This analysis clearly indicate, that the defined in Fig.1 yellow and red layers, can be attributed to an airmass that likely contained the biomass burning particles from the wild-fires originating in Eastern Europe (mostly Ukraine: in red; and likely Belarus: in yellow). Indeed, one of the standard MODIS products which is shown in Fig.3, depicts the accumulated locations of the fires detected by MODIS on board of the Terra and Aqua satellites passing over Europe and Western Asia. The composite shown in Fig. 3 was obtained over a 10-day period from $9^{\text {th }}$ to $18^{\text {th }}$ August 2015, which most closely coincide with the analyzed period. Also the MODIS 10-days fire composite obtained before August $9^{\text {th }}$, indicated fire activity in this area; it is not shown here for brevity. Note that, each colored dot indicates a location where MODIS detected at least one fire during the composition period. Moreover, the plume of smoke from the peat-lands fires that occurred in vicinity of the Chernobyl nuclear power plant exclusion zone was captured at the Terra MODIS image of $10^{\text {th }}$ August 2015 (not shown here for brevity). In Fig.1, in green, the air-masses from the West, and probably also from the Western Sahara seem to have brought the pollution that was likely mixed with the mineral dust particles. For this layer, the lidar derived linear depolarization was higher and the lidar derived relative humidity was low. However, this layer is difficult to define. In Fig.1, in violet, we have likely a mixture of aerosols that were transported from the East and the South of Europe, remaining very close to the ground on the entire transport pathway. The interpretation of the optical properties of this data is challenging. According to the backward trajectories, the dark blue air-masses in Fig. 1 seem to have circulated very close to the surface over the southern border of Poland, The Czech Republic and Slovakia about 3 to 9 days before they were arriving in Warsaw. Also here the interpretation of the data is not a straight forward one.

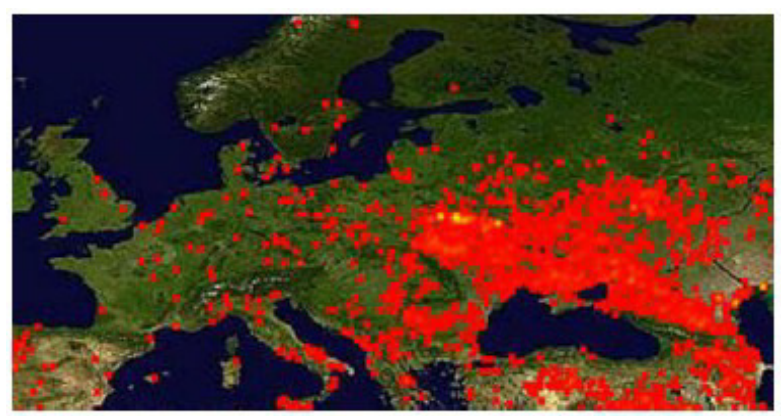

Figure 3 The MODIS global fire map for 09-18 August 2015 , color ranges from red where the fire count is low to yellow where number of fires is large.

In the same figure, in the area that is depicted in light-blueish and gray color, we discern layers with the origin found very hard to be assessed. For both of these layers, the ensemble backwardtrajectories point either into the western Europe or to Ukraine. In both layers, similar optical properties and low values of relative humidity were derived from the lidar data. However, we treat the two layers separately, as the light-blueish one seems to be very weekly defined with a little higher particle linear depolarization ratios, than in the gray layer. Finally, in Fig.1 in pink, there is an aerosol that was suspended within the boundary layer, that was ascending by the convection during the day, and reaching at the maximum at around $2 \mathrm{~km}$ - typical height for summer-time well mixed 
boundary layer in Warsaw. Thus it is likely that within the pink layer a typical polluted anthropogenic urban aerosol was captured.

\section{CONCLUSIONS}

For selected times on August $10^{\text {th }}$, from the lidar signals approximately averaged over $45 \mathrm{~min}$ for every consecutive hour over the day, the particle extinction and backscatter coefficients profiles, as well as the particle linear depolarization ratio profiles were obtained (not shown for brevity). For these profiles, also the related lidar ratios at $355 \mathrm{~nm}$ and $532 \mathrm{~nm}$, and the extinction Angström exponents at both wavelengths were calculated.

In general, in the main layers, the obtained results reveal different features than typical biomass burning values observed over Warsaw $[6,8,9]$. Here, high lidar ratios in the range of 84-98 sr at $355 \mathrm{~nm}$ and $72-88 \mathrm{sr}$ at $532 \mathrm{~nm}$. The extinctionrelated Ångström exponent was from 1.1 to 1.7. A relatively low volume linear depolarization of $0.9-2.0 \%$ at $355 \mathrm{~nm}$ and $1.9-2.7 \%$ at $532 \mathrm{~nm}$ was obtained. In some cases, e.g. as in Fig.2, left at 3$4 \mathrm{~km}$ and right around $2.5 \mathrm{~km}$, the depolarizing layer (values up to in this layer 4.6\%) was clearly observed only above the backscattering layer. Such a shift is not unusual for the layers in which the biomass burning particles are observed along with the mineral dust particles, which likely seem to occurred on that day.

\section{OUTLOOK}

In the near future, we are planning to extend this study, mainly for calculating the sets of optical properties for data obtained on other days during the event. The manual aerosol typing was found to hinder the analysis, as time consuming. Thus, use of advanced automated approach for accurate definition of existing layers is planned. Finally, retrieval of particles micro-physical parameters for specific layers of interest that will be defined based on holistic view on the event shall follow.

\section{ACKNOWLEDGEMENTS}

The development of the PollyXT-UW lidar was financed by the Polish Foundation of Science and Technology FNTP-No.519/FNITP/115/2010.

This work was partly financed by ESA-ESTEC Contract 4000119961/16/NL/FF/mg (POLIMOS).

\section{References}

[1] Engelmann, R., et al.: The automated multiwavelength Raman polarization and water-vapor lidar PollyXT: the neXT generation, Atmos. Meas. Tech., 9, 1767-1784, doi:10.5194/amt-9-1767-2016, 2016.

[2] Althausen, D., et al.: Polly NET - a network of multiwavelength polarization Raman lidars, Proc. SPIE, Lidar Technologies, Techniques, and Measurements for Atmospheric Remote Sensing IX，Dresden, 23-26 Sept 2013, 88940I paper no.17, 2013.

[3] Pappalardo, G., et al.: EARLINET towards an advanced sustainable European aerosol lidar network, Atmos. Meas. Tech., 7, 2389-2409, 2014.

[4] Baars, H., et al.: An overview of the first decade of PollyNET: an emerging network of automated Raman-polarization lidars for continuous aerosol profiling, Atmos. Chem. Phys., 16, 5111-5137, 2016.

[5] Freudenthaler, V., et al.: Depolarization ratio profiling at several wavelengths in pure Saharan dust during SAMUM 2006, Tellus B, 61(1), 165-179, 2009.

[6] Stachlewska I.S., Costa-Suros M., Althausen D.: Raman lidar water vapor profiling over Warsaw, Poland, Atmospheric Research, vol. 194, 15 September 2017, pp. 258-267, DOI 10.1016/j.atmosres.2017.05.004, 2017.

[7] Draxler, R. R., Rolph, G. D., 2010: HYSPLIT accessed via NOAA ARL READY Website (http://ready.arl.noaa.gov/HYSPLIT.php)

[8] Janicka L., Stachlewska I.S., Veselovskii I., Baars H.: Temporal variations in optical and microphysical properties of mineral dust and biomass burning aerosol derived from daytime Raman lidar observations over Warsaw, Poland, Atmospheric Environment, vol. 169, pp. 162174, doi:10.1016/j.atmosenv.2017.09.022, 2017

[9] Ortiz-Amezcua P., Guerrero-Rascado L.L., Granados-Muñoz M.J., Benavent-Oltra J.A., Böckmann Ch., Samaras S., Stachlewska I.S., et al., Microphysical characterization of longrange transported biomass burning particles from North America at three EARLINET stations, Atmos. Chem. Phys., 17, 5931-5946, doi:10.5194/acp-17-5931-2017, 2017. 